\title{
A Rustic Opinion on the Adaption of Internet Literature to Film and TV Works
}

\author{
LIU Shikun \\ College of Media and Communication, Zaozhuang University, P.R.China, 277160 \\ Email: 79210118@qq.com
}

\begin{abstract}
The purpose of this article is to introduce the concept of Internet literature, and to analyze the current situation of the adaptation of the film and television works from the Internet literature. By guiding the creator to make a benign creation and adaptation, the above will help create more and more excellent film and television works. Case analysis, data analysis and other methods are used in this article to summarize and classify the audience groups of Internet literature. Finally, this article comes to a conclusion that the adaptation of film and television works from Internet literature must have the conditions to guide the perfect "cross boundary" of Internet literature and film and television works.
\end{abstract}

Keywords-Audience rating; TV series; Internet literature

\section{INTRODUCTION}

Film has been invented for more than 120 years. It has become a mature and stable cultural form for mankind to express imagination, thought, emotion and gain knowledge, aesthetics and entertainment by means of film and television images. From the moment when the film was first born, it began to keep an inseparable predestination with literature. China's first film "Ding Jun Shan" is derived from the classic literature works "Romance of the Three Kingdoms". But then as the film developed and matured as an independent art, countless filmmakers tried to draw a line between film and literature, which can been reflected from the sayings of "Whether the film is the vassal of literature" before 1949, "Film should discard the crutches of the drama.", "Film should discard the crutches of literature." of the fourth, fifth generation of directors after 1949. But throughout the history of Chinese film and even the history of world film, most famous works are closely related to literature and even directly derived from literary works.

Classics such as "Godfather", "Kill a Mockingbird", "Rashomon", "Red Sorghum" and "Farewell My Concubine" are all adapted from literary works. In recent years, Internet literature is blooming with the popularity of the Internet and the mobile Internet, and the film and television works based on Internet literature are becoming more and more popular, such as "Time Raiders", "The Ghouls", "Yu sin", "Love O2O" and so on. It is widely seen and discussed in young viewing groups [1].

\section{THE EMERENGING AND DEVELOPMENT OF INTERNET LITERATURE}

Internet novels in our country have been born for a long time. The initial Internet literature was born with the rise of the Internet. In the 90s of last century, the first influential network novel, "the first close contact" [2], appeared. In this novel, the love story between the character "Pizi Cai" and "Qingwufeiyang" influences a large number of people and become an important symbol of Internet literature. After a long period of time, online romance became the most important theme of Internet literature.

The strong development of film and TV works adapted from online novels is closely related to the rise of Internet novels. Since the Internet entered China, especially with the rapid development of mobile media, more and more people have entered the network reading space. A large number of web literature websites such as "Hongxiutianxiang" and "China Qidianwenxue" are born. Online writers rely on these free and community-based websites to release their own ideas and create many popular novels, such as the "Time Raiders" of Nanpaisanshu the "Doupocanaqiong" of Tiancantudou. Since then, a series of excellent network novels such as "Yu sin", "candle in the tomb "Love O2O" are also springing up and have a great influence.

According to statistics, till the end of December 2017, the scale of Internet Literature users in China has reached 378 million, and the development of Internet literature is ahead of the world.

In the course of the development of network literature, we can find that the creation of Internet literature has an inseparable connection with the interests and aesthetic needs of the audience. They complement each other, and with the help of the rapid spreading speed of Internet literature, the information between the author and the readers is frequent and efficient. With positive feedback from readers, network works can be improved with targets, so that they can be better spread and promoted. 


\section{THE SURVIVAL AND DEVELOPMENT OF FILM AND TV WORKS ADAPTED FROM INTERNET LITERATURE}

According to the order of time, the process of China film adaptation from Internet literature can be roughly divided into three stages. The first stage is before the year 2003, it was thought to be the barbarous period of the film and television adaptation of the network literature. The most famous case of this period was Internet novel "First intimate contact" created by the Taiwan writer Cai Zhiheng in 1998. It was a literary work which is so popular in the Mainland, Taiwan and Hong Kong in the emerging period of Internet literature. Then the novel was adapted to a same-named film directed by director Jin Guozhao, played by Jordan Chan, Hsu Chi and Chang Chen. And almost at the same time, the same named TV play appeared in mainland, played by Tong Dawei, which can reflect the influence of the novel. But because the whole Internet culture was still in the embryonic stage, and the influence of the network literature itself was negligible in this context, the Internet literature in this period did not enter the vision of the mainstream film makers. The second stage, which started from 2004 to the next 5 years, can be considered the growth stage of the adaptation of the network literature to film and TV works. The most popular of this stage is the series of novels by the horror writer Cai Jun, such as "The World", "The Revolving Door", "The Ghost Inn", "The Curse" and so on. Cai Jun's horror novels do not only involve Internet literature, but also include traditional publishing houses and magazine publications. The famous horror movie "the Kroraina of death" is adapted from Cai Jun's online novel "Curse". Because of the popularity of the network and even the appearance of handheld reading, such as mobile phone and electric paper book, network literature has been paid more attention to in this period Therefore, the overall production level of the adaptation of film and TV works has been improved because more and more film and television practitioners get involved. The third stage is from 2009 to the present. In this stage, the network culture began to prevail, and with the popularity of the mobile Internet, people read Internet literature through the high definition, large screen electric paper books, large screen smart phone. Many Internet literature writers become "Internet celebrity". In this stage, a large number of excellent literary works and the film and television works adapted from them emerged. In this stage, network literature adaption of Internet literature to film and television works has become a mature cultural industry. Many writers have even reached agreement with publishers and film and television production institutions in the stage of literary creation. There are many mature and adapted works at this stage, the quality and artistic value of the works are not the same with those of the previous two stages. In this background, even some older fifth generation directors poured into the big tide, such as the "Under the Hawthorn Tree "in 2010, which was made by the famous fifth generation director Zhang Yimou. The literary original of this film is the same name network novel written by Chinese American Amy, which proved to be a successful adaptation. It not only ease the trust crisis of several "blockbusters" of Zhang Yimou's previous martial arts, but also make two young talents - Dongyu Zhou and Dou Xiao popular, who are now active in the movie world.
Since its birth, network literature has been plagued because of the author's low remuneration and the unitary mode of conversion, which has made the value of network literature very limited for a long time. In recent years, the adaptation of film and television works can be regarded as a successful attempt to explore the new mode of conversion. As the state promotes economic transformation and vigorously develops cultural industries, the government has paid more attention to the protection of intellectual property rights. Many excellent works of network literature have been adapted by film and television works and even network games which are known by the public. From the films and even TV dramas adapted from "Silent Separation" and then to the "Nirvana in Fire" which sweeped the major TV and video websites in 2015, it has become the cultural focus of the hot discussion in the streets and lanes. These successful adaptation cases are enough to show the arrival of the era of the bloom of Internet literature. Behind the heat of film and television works, with the rise of copyright, the income of Internet writers is becoming more and more reasonable, and the mode of conversion is even diversified because the writer becomes "Internet Celebrity". In the 2016 Chinese writers' list of fortune, the author of "flower bone", Guoguo ranked thirty-third, earning 4 million RMB annual royalty income. The author of "Silent Separation", Gu Man, hit the list again with an annual royalty income of 3 million RMB. The authors of other Internet literature works such as "The Legend of Miyue" 'WuXin' 'Time Raiders" "Candle in the Tomb", also hit the list with their rich income. The rich income, in turn, can stimulate the creative enthusiasm of the creator, which is a mutually beneficial and win-win good for the network literature and the domestic film and television industry.

\section{ANALYSIS OF THE REASONS FOR THE UPSURGE OF THE ADAPTATION OF FILM AND TV WORKS FROM THE INTERNET NOVELS}

Compared to judging excellent traditional literary works, which needs extensive word of mouth, time accumulation and authority recognition. The novel which can be highly sought in the network often has a more simple and rough criterion. That is, the works must have a wide reading base and an impressive click rate. In such a market atmosphere, there are outstanding writers such as Tangjiasanshao Nanpaisanshu who have very high popularity and stable readers. Even similar to the rules of the film industry. the name of the writer itself has the brand effect, for example, Chang Shuxin's novel "Yu sin" has an accumulative reader amount over 430 million since its publish. After the broadcast of the TV series, the audience ratings remained high. In the first season, it ratings broke 100 million in 72 hours and 200 million on the Internet for a week. A famous online novel itself has a large number of fans, which have reduced the risk of shooting investment. In addition, traditional literature, due to higher royalty, increases the cost of production by film and television institutions. Compared with it, the royalty rate of the Internet publications is relatively low, which can greatly save the investment of the early creation. What's more, these Internet literature publications themselves have been sitting on a large base of audience before becoming a film and television series. This part of the literary enthusiasts is also considered to be the potential audience for film and 
television dramas and the main force of the box office contribution. The success of the network fiction adaptation of the film and television works will also feed back the literary creation. After the box office sale or the hot broadcast of the drama, it will expand more audience groups for the original author and promote the continuous high fever of the original work.

For the producers, the colorful network literature can enrich the theme of TV drama, and alleviate the very embarrassing and homogeneous competition in the film and TV industry in China. As a typical cultural industry, in order to meet the market and cost considerations, production-line is the only way, but many TV plays are just follow the hot spot. It can often be seen that a TV play of the same type and subject on all channels, which is a great harm to the whole film and television industry. The imagination of online novels can make up for the problems of self duplication, originality and lack of plot in the creation of films and TV plays. Larger Internet original literary websites like Qidian and Jinjiang basically include the mainstream themes of the current novels. Whether the web novel creators or its content is more appropriate, the main audience group is a young person. This part of the audience, regardless of reading or viewing, wants to see the shadow of his life in the art works, and even hopes to get "guidance" or "solution" to his own living or predicament. For example, young people are most concerned about high house prices, marriage and love, child support and other issues, we can see from a lot of works, such as a series of TV dramas "Naked Marriage", "Little dad", "Dwelling Narrowness" and so on. In addition, the time-travel subject matter such as".

Jade Palace Lock Heart", the subject of the fairy tale of "Ten great III of peach blossom", the mysterious subject matter such as "breaking the sky", the historical themes such as "the things of the Ming Dynasty", and the theme of the campus romance such as "So Young" and so on, are giving the film and television dramas lot of new choices, greatly relieves the phenomenon of homogenization competition, and seeks the progress of self in constantly renewing the audience's aesthetic demand. The popularity of this kind of film and TV play is a good thing for film and television practitioners, Internet literature creators, audiences and even the entire cultural industry.

As the main audience group is young, this kind of work needs more active and effective marketing strategies to compete with other forms of entertainment or cultural consumption. Behind the success of a hit show, there is a strong marketing team and effective marketing strategies. Taking Hunan TV's"

The Journey of Flower" and "The Legend of Chu Qiao" as an example, Hunan Satellite TV uses "network linkage", a modern cross media cooperation form based on network and television, which is based on network and television. With the continuous improvement of social media in recent years, people will spend a lot of time on social applications such as Weibo and WeChat, and marketing through social media has become the most important means of publicity of the film and television institutions. Hunan TV has adapted well to the change of this mode of communication. It has expanded the channel of network broadcasting with the new media, making the film and television works adapted from the Internet literature back to its birthplace ---Internet.

For the relationship between the content creator of film and television works and the audience, the creation process of the network novel is also the process of interaction and communication between the two parties, which greatly satisfies the people's individualized demand for cultural consumption. Readers can explore the development of the plot through the message on the literary website, and express their opinions on the works, and point out their advantages and disadvantages. From the perspective of online novels adapted to film and television drama, the interaction between film producers and the audience has broken the previous single linear mode of communication. The Internet platform gives everyone a chance to experience a writer or director's life. Therefore, the film and TV dramas adapted from the popular network novels have grasped the audience's aesthetic psychology and preference in a timely and comprehensive way, and can quickly complete the self innovation from content to form so as to win the initiative of the battlefield of the audience ratings.

\section{CONCLUSION}

With the rapid development of the cultural industry and the vigorous consumption of the public spirit, the film and television works adapted from the Internet literature have greatly promoted the industry. However, we should also be vigilant. Compared to the traditional literary works, the works of network literature still have great progress in the overall artistic level and aesthetic interest. In addition, driven by the anxiousness of quick profits, there are still some low-quality Internet works adaption which are crudely made and overdrawn market. It is hoped that as the cross boundary combination---"Internet literature" and "film and television" are increasingly closely linked, the development of the industry is becoming more and more mature and standardized, producing more excellent works.

\section{ACKNOWLEDGMENT}

Author in brief:

Liu Shikun, Male, 39 years old, Associate Professor of College of Media and Communication, Zaozhuang University, Shandong.

Main Research Directions: Film and Television Production and Film Review

\section{REFERENCES}

[1] Wang Qiang, The Rise and Development of Internet Literature, People's Daily,2000-11-11(in Chinese)

[2] Nie Xinyue, Analysis of Film and TV adaptation of Chinese Internet Novel, 2016-06-10 (in Chinese) 